\title{
Trypanocidal activity of the proteasome inhibitor and anti-cancer drug bortezomib Dietmar Steverding* and Xia Wang
}

\author{
Address: BioMedical Research Centre, School of Medicine, Health Policy and Practice, University of East Anglia, Norwich, NR4 7TJ, UK \\ Email: Dietmar Steverding* - dsteverding@hotmail.com; Xia Wang - xiawang@ hotmail.com \\ * Corresponding author
}

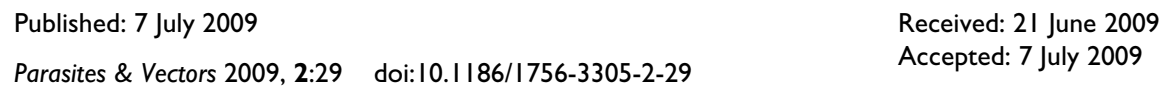

This article is available from: http://www.parasitesandvectors.com/content/2/1/29

(C) 2009 Steverding and Wang; licensee BioMed Central Ltd.

This is an Open Access article distributed under the terms of the Creative Commons Attribution License (http://creativecommons.org/licenses/by/2.0), which permits unrestricted use, distribution, and reproduction in any medium, provided the original work is properly cited.

\begin{abstract}
The proteasome inhibitor and anti-cancer drug bortezomib was tested for in vitro activity against bloodstream forms of Trypanosoma brucei. The concentrations of bortezomib required to reduce the growth rate by $50 \%$ and to kill all trypanosomes were $3.3 \mathrm{nM}$ and $10 \mathrm{nM}$, respectively. In addition, bortezomib was 10 times more toxic to trypanosomes than to human HL-60 cells. Moreover, exposure of trypanosomes to $10 \mathrm{nM}$ bortezomib for $16 \mathrm{~h}$ was enough to kill $90 \%$ of the parasites following incubation in fresh medium. However, proteasomal peptidase activities of trypanosomes exposed to bortezomib were only inhibited by 10\% and 30\% indicating that the proteasome is not the main target of the drug. The results suggest that bortezomib may be useful as drug for the treatment of human African trypanosomiasis.
\end{abstract}

\section{Findings}

Human African trypanosomiasis or sleeping sickness is a fatal disease caused by the protozoan parasite Trypanosoma brucei. The parasites live and multiply extracellularly in the blood and tissue fluids in the human host and are transmitted by the bite of infected tsetse flies (Glossina spp.). Millions of people living in 36 sub-Saharan countries are threatened with the disease and the estimated number of infected people is currently between 50,000 and 70,000 [1]. There are only four drugs available for chemotherapy of sleeping sickness and all show some degree of toxic side effects [2]. In addition, drug resistance in T. brucei is an increasing problem [3,4]. Moreover, at the turn of the millennium, the production of anti-sleeping sickness drugs was under threat as their manufacture was not profitable [5]. Thus, new strategies for the development of new drugs for treatment of sleeping sickness are urgently needed.
One route for the discovery of new anti-sleeping sickness drugs is the screening of existing drugs for trypanocidal activities [6]. For example, agents that have been developed as potential anti-cancer drugs could also be of use against human African trypanosomiasis as has been shown for the ornithine decarboxylase inhibitor eflornithine [7]. Proteasome inhibitors represent a new class of anti-cancer drugs and have recently been shown to display promising anti-trypanosomal activities [8-12]. In this study, we investigated the effect of the proteasome inhibitor bortezomib (Fig. 1) on bloodstream forms of T. bru$c e i$. Bortezomib (Velcade ${ }^{\circledast}$ ) is a novel chemotherapeutic agent for multiple myeloma and mantle cell lymphoma, and was approved by the FDA for treatment of these malignancies in 2003 and 2006, respectively [13].

The trypanocidal activity of bortezomib was determined with T. brucei bloodstream forms 427-221a while the gen- 


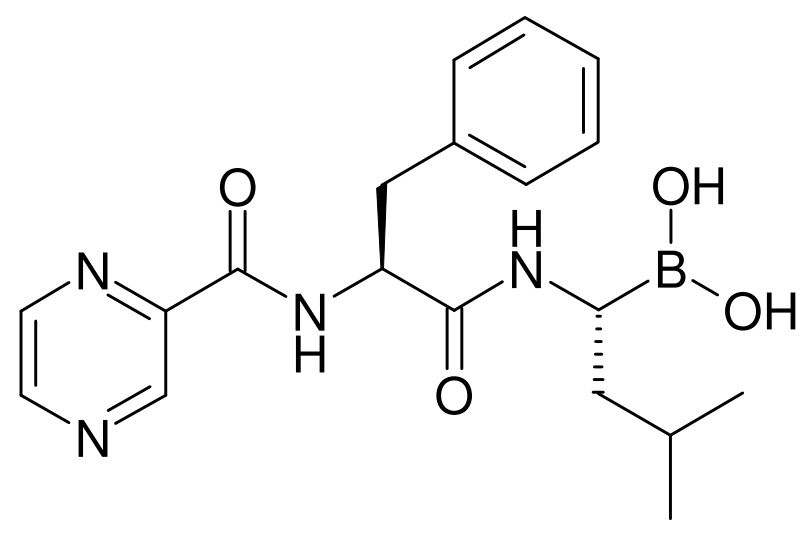

Figure I

Chemical structure of bortezomib. Bortezomib ([(IR)3-methyl-I-(\{(2S)-3-phenyl-2-[(pyrazin-2-ylcarbonyl)amino]propanoyl\}amino)butyl]boronic acid) is marketed as Velcade ${ }^{\circledR}$ by Millennium Pharmaceuticals and currently used to treat people with multiple myeloma.

eral cytotoxicity of the drug was evaluated with human myeloid leukaemia HL-60 cells. The tests were analysed by the Alamar Blue assay as described previously [14]. In brief, cells were seeded in 24-well plates in a final volume of $1 \mathrm{ml}$ of appropriate culture medium (trypanosomes: Baltz medium plus $16.7 \%$ heat-inactivated foetal bovine serum [15]; HL-60 cells: RPMI 1640 plus 16.7\% heat-inactivated foetal bovine serum) containing various concentration of bortezomib and 1\% DMSO. Wells containing medium and 1\% DMSO served as controls. The initial densities were $10^{4} / \mathrm{ml}$ for trypanosomes and $10^{5} / \mathrm{ml}$ for HL-60 cells. After $24 \mathrm{~h}$ incubation, $100 \mu \mathrm{l}$ Alamar Blue (11.11 mg resazurin sodium salt in $100 \mathrm{ml}$ PBS) was added and the cells were incubated for a further $48 \mathrm{~h}$ so that the total incubation time was $72 \mathrm{~h}$. Then, the plates were read on a microplate reader using a test wavelength of $570 \mathrm{~nm}$ and a reference wavelength of $630 \mathrm{~nm}$. The $50 \%$ growth inhibition $\left(\mathrm{GI}_{50}\right)$ values, i.e. the concentration of the drug necessary to reduce the growth rate of trypanosomes and HL- 60 cells by $50 \%$ to that of controls, was determined by linear interpolation according to the method described in [16]. The minimum inhibitory concentration (MIC) values, i.e. the concentration of the drug at which all trypanosomes and HL-60 cells were killed, was determined microscopically.

Bortezomib showed a dose-dependent effect on the growth of $T$. bruce $i$ bloodstream forms with a $\mathrm{GI}_{50}$ value of $3.3 \mathrm{nM}$ and a MIC value of $10 \mathrm{nM}$ (Fig. 2). For comparison, the trypanocidal activity of the commercial antisleeping sickness drug melarsoprol was determined under the same experimental conditions. Melarsoprol exhibited a $\mathrm{GI}_{50}$ value of $3.8 \mathrm{nM}$ and a MIC value of $100 \mathrm{nM}$ (Fig. 2).

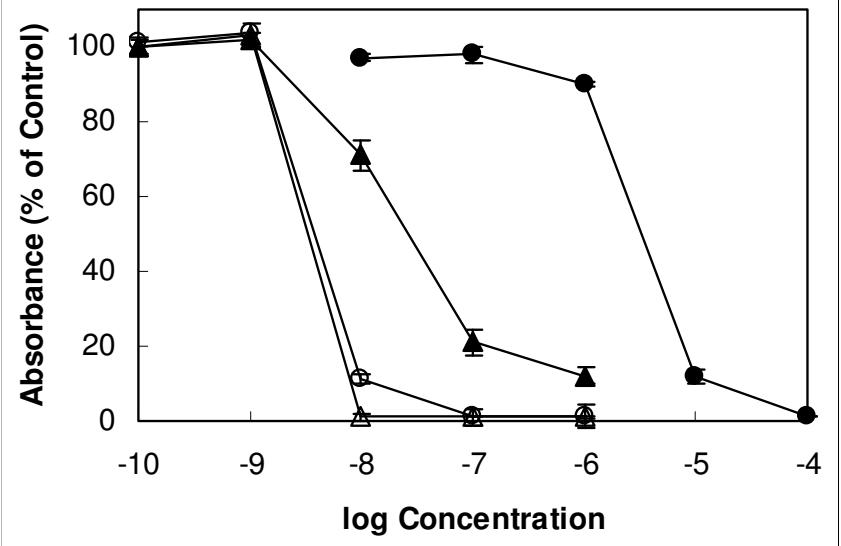

Figure 2

Effect of bortezomib and melarsoprol on the growth of bloodstream forms of T. brucei and human myeloid leukaemia HL-60 cells. Trypanosomes (open symbols) and HL-60 cells (closed symbols) were incubated with varying concentrations of bortezomib (triangles) and melarsoprol (circles). After $72 \mathrm{~h}$ of culture, cell viability and proliferation were determined with the colorimetric dye resazurin. Mean values \pm SD of four experiments are shown.

Thus, the trypanocidal activity of bortezomib was similar to melarsoprol with respect to the $\mathrm{GI}_{50}$ value and was 10 times greater with respect to the MIC value. As can be expected from a drug to treat hematologic malignancies, bortezomib exhibited also cytotoxic activity against HL60 cells with a $\mathrm{GI}_{50}$ value of $26.7 \mathrm{nM}$ and a MIC value of $100 \mathrm{nM}$ (Fig. 2). The $\mathrm{GI}_{50}$ value of bortezomib for HL-60 cells is within the range of the average $\mathrm{GI}_{50}$ value of $7 \mathrm{nM}$ for the drug across 60 tumour cell lines (including HL-60 cells) [17]. Melarsoprol, on the other hand, was much less toxic to HL-60 cells, displaying a $\mathrm{GI}_{50}$ value of $3260 \mathrm{nM}$ and a MIC value of $10,000 \mathrm{nM}$ (Fig. 2). As a result, the $\mathrm{GI}_{50}$ and MIC ratios of cytotoxic/trypanocidal activities (selectivity indices) for bortezomib were less favourable $\left(\mathrm{GI}_{50}\right.$ ratio $=8$; $\mathrm{MIC}$ ratio $\left.=10\right)$ than that of the anti-sleeping sickness drug melarsoprol $\left(\mathrm{GI}_{50}\right.$ ratio $=860$; $\mathrm{MIC}$ ratio $=100)$.

To check whether the trypanocidal activity of bortezomib is due to inhibition of the proteasome, the activity of this multi-enzyme complex in trypanosomes exposed to the drug was determined. In this experiment, $10^{7}$ trypanosomes/ml were incubated with or without $100 \mu \mathrm{M}$ bortezomib for $2 \mathrm{~h}$. After washing three times with PBS/1\% glucose, the trypanosomes were lysed in $10 \mathrm{mM}$ Tris, 2 mM ATP, 0.1 mM EDTA, pH 7, 1 mM DTT, 0.2\% NP-40 and centrifuged at $16000 \times g$. The chymotrypsin-like activity and the trypsin-like activity of the clarified supernatant were assayed in $50 \mathrm{mM}$ HEPES, pH 7.5 with $10 \mu \mathrm{M}$ SucLLVY-AMC and $10 \mu \mathrm{M}$ Z-GGR-AMC, respectively. Surpris- 
ingly, bortezomib inhibited the chymotrypsin-like activity and the trypsin-like activity of the proteasome in trypanosomes only by $30 \%$ and $10 \%$, respectively. Under the same experimental conditions, the drug inhibited the proteasomal chymotrypsin-like and trypsin-like activity in HL-60 cells by $100 \%$ and $90 \%$, respectively. These findings indicate that the trypanocidal action of bortezomib is most likely not the result from inactivation of the proteasome.

For treatment of multiple myeloma, the recommended dose and treatment schedule of bortezomib is $1.3 \mathrm{mg} / \mathrm{m}^{2}$ administered as a 3 to 5 second bolus intravenous injection on days $1,4,8$ and 11 of a three week cycle, for up to 8 cycles [18]. Pharmacokinetic/pharmacodynamic studies showed that on day 11 the mean plasma concentration of bortezomib falls from $422 \mathrm{nM}$ to $10 \mathrm{nM}$ within $16 \mathrm{~h}$ of administration of the drug [19]. As $10 \mathrm{nM}$ is the MIC value of bortezomib, we wanted to investigate whether exposure of trypanosomes to $10 \mathrm{nM}$ of the drug for $16 \mathrm{~h}$ is long enough to kill the parasites. To this end, $5 \times 10^{5}$ trypanosomes $/ \mathrm{ml}$ were treated with or without $10 \mathrm{nM}$ bortezomib for $16 \mathrm{~h}$, then diluted to $10^{4}$ cells $/ \mathrm{ml}$ in fresh medium for further incubation and counted every $24 \mathrm{~h}$ using a Neubauer haemocytometer. For the first $48 \mathrm{~h}$ of reincubation, the densities of cultures containing trypanosomes that had been exposed to bortezomib decreased continuously (Fig. 3). Thereafter, the numbers of trypanosomes started to increase but did not reach those of control cultures (Fig. 3). This result shows that treatment of trypanosomes with $10 \mathrm{nM}$ bortezomib for $16 \mathrm{~h}$ leads in the killing of $90 \%$ of the parasites.

In conclusion, bortezomib has been shown to display substantial trypanocidal activity. The current therapy regime of bortezomib to treat cancer is probably not applicable for treatment of sleeping sickness. The results of this study indicate that a shorter treatment regime with a higher dosage may be appropriate. Importantly, bortezomib can be also administered subcutaneously [19] whereas most of the current anti-sleeping sickness drugs have to be given intraveneously [21]. Before developing bortezomib as an anti-sleeping sickness drug, animal experiments would need to be performed to establish the in vivo efficacy of this proteasome inhibitor. However, a selectivity index of 10 may be regarded as insufficient for proceeding to animal experiments. The Special Programme for Research and Training in Tropical Diseases at the World Health Organization (WHO/TDR) recommends a selectivity index of $>100$ to pursue such animal studies [22]. Compared with normal cells, however, the cytotoxicity of bortezomib determined for HL-60 cells may be overestimated. In addition, bortezomib may serve as a lead for the development of analogues with improved selectivity. Another possibility would be to use borte-

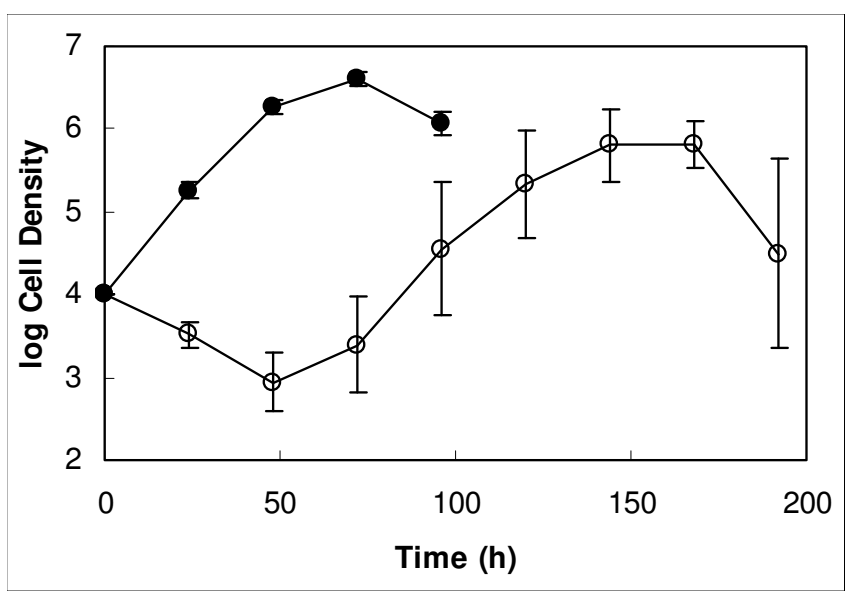

Figure 3

Effect of pre-incubation with bortezomib on the growth of bloodstream forms of T. brucei. Trypanosomes $\left(5 \times 10^{5} / \mathrm{ml}\right)$ were incubated in the presence (open circles) or absence (closed circles) of $10 \mathrm{nM}$ bortezomib for $16 \mathrm{~h}$. Thereafter, trypanosomes were diluted to a cell density of $104 / \mathrm{ml}$ in fresh medium and further incubated. At the indicated time points, trypanosomes were counted using a Neubauer haemocytometer. Geometric means \pm SD of four experiments are shown. In control cultures, parasites died between 96 and $120 \mathrm{~h}$ of cultivation as has been shown previously [20]. In bortezomib-treated cultures, parasites died between 192 and $264 \mathrm{~h}$ of cultivation.

zomib in combination with the current drugs to treat sleeping sickness. Such drug combination regimes may lead to synergistic effects, in which lower amounts of drugs sufficient to kill the parasites would lead to a reduction in toxicity.

\section{Competing interests}

The authors declare that they have no competing interests.

\section{Authors' contributions}

XW and DS carried out the experiments. DS conceived the study and prepared the final draft of the manuscript. All authors read and approved the final manuscript.

\section{Acknowledgements}

We thank Dr Penelope Powell for critical reading of the manuscript.

\section{References}

I. Steverding D: The history of African trypanosomiasis. Parasit Vectors 2008, I:3.

2. Fairlamb AH: Chemotherapy of human African trypanosomiasis: current and future prospects. Trends Parasitol 2003, 19:488-94.

3. Matovu E, Seebeck T, Enyaru JCK, Kaminsky R: Drug resistance in Trypanosoma brucei spp., the causative agents of sleeping sickness in man and nagana in cattle. Microbes Infect 2001, 3:763-70.

4. Delespaux V, de Koning HP: Drugs and drug resistance in African trypanosomiasis. Drug Resist Updat 2007, 10:30-50. 
5. Wickware P: Resurrecting the resurrection drug. Nat Med 2002, 8:908-9.

6. Caffrey CR, Steverding D: Recent initiatives and strategies to developing new drugs for tropical parasitic diseases. Expert Opin Drug Discov 2008, 3:173-86.

7. Barrett SV, Barrett MP: Anti-sleeping sickness drugs and cancer chemotherapy. Parasitol Today 2000, 16:7-9.

8. Nkemgu-Njinkeng J, Rosenkranz V, Wink M, Steverding D: Antitrypanosomal activities of proteasome inhibitors. Antimicrob Agents Chemother 2002, 46:2038-40.

9. Glenn RJ, Pemberton AJ, Royle HJ, Spackman RW, Smith E, Rivett AJ, Steverding D: Trypanocidal effect of $\alpha^{\prime}, \beta^{\prime}$-epoxyketones indicates that trypanosomes are particularly sensitive to inhibitors of proteasome trypsin-like activity. Int J Antimicrob Agents 2004, 24:286-9.

10. Steverding D, Spackman RW, Royle HJ, Glenn RJ: Trypanocidal activities of trileucine methyl vinyl sulfone proteasome inhibitors. Parasitol Res 2005, 95:73-6.

II. Steverding D, Pemberton AJ, Royle H, Spackman RW, Rivett AJ: Evaluation of the anti-trypanosomal activity of tyropeptin $A$. Planta Med 2006, 72:76I-3.

12. Steverding D: The proteasome as a potential target for chemotherapy of African trypanosomiasis. Drug Dev Res 2007, 68:205-I2.

13. Utecht KN, Kolesar J: Bortezomib: a novel chemotherapeutic agent for hematologic malignancies. Am J Health Syst Pharm 2008, 65:|22|-3|.

14. Merschjohann K, Sporer F, Steverding D, Wink M: In vitro effect of alkaloids on bloodstream forms of Trypanosoma brucei and $T$. congolense. Planta Med 200I, 67:623-7.

15. Baltz T, Baltz D, Giroud C, Crockett J: Cultivation in a semidefined medium of animal infective forms of Trypanosoma brucei, $T$. equiperdum, T. evansi, $T$. rhodesiense and $T$. gambiense. $E M B O$ J I 985, 4: I273-7.

16. Huber W, Koella JC: A comparison of three methods of estimating $E C_{50}$ in studies of drug resistance of malaria parasites. Acta Trop 1993, 55:257-6I.

17. Adams J, Palombella VJ, Sausville EA, Johnson J, Destree A, Lazarus DD, Maas J, Pien CS, Prakash S, Elliot PJ: Proteasome inhibitors: a novel class of potent and effective antitumor agents. Cancer Res 1999, 59:2615-22.

18. Millennium Pharmaceuticals Inc: Velcade ${ }^{\circledR}$ (bortezomib) for injection. Full prescribing information. Cambridge, MA, USA; issued June 2008. [http://velcade.com/full prescrib velcade.pdf].

19. Moreau P, Coiteux V, Hulin C, Leleu X, van de Velde H, Acharya M, Harousseau JL: Prospective comparison of subcutaneous versus intravenous administration of bortezomib in patients with multiple myeloma. Haematologica 2008, 93:1908-II.

20. Hesse F, Selzer PM, Mühlstädt K, Duszenko M: A novel cultivation technique for long-term maintenance of bloodstream form trypanosomes in vitro. Mol Biochem Parasitol 1995, 70:157-66.

21. Kuzoe FA: Current situation of African trypanosomiasis. Acta Trop 1993, 54:153-62.

22. Nwaka S, Hudson A: Innovative lead discovery strategies for tropical diseases. Nat Rev Drug Discov 2006, 5:941-55.
Publish with Biomed Central and every scientist can read your work free of charge

"BioMed Central will be the most significant development for disseminating the results of biomedical research in our lifetime. "

Sir Paul Nurse, Cancer Research UK

Your research papers will be:

- available free of charge to the entire biomedical community

- peer reviewed and published immediately upon acceptance

- cited in PubMed and archived on PubMed Central

- yours - you keep the copyright

Submit your manuscript here:

http://www.biomedcentral.com/info/publishing_adv.asp
BioMedcentral 